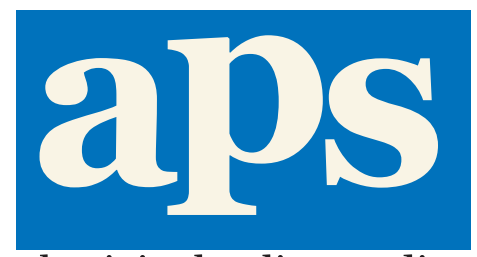

aboriginal policy studies

\title{
Article
}

\section{Seeing Like a Circle: Perspectives on the Field from a Dialogue on Urban Aboriginal Economic Development}

\author{
Charles L. Horn and Greg Halseth
}

aboriginal policy studies, Vol. 1, no. 2, 2011, pp. 101-131

This article can be found at:

http://ejournals.library.ualberta.ca/index.php/aps/article/view/9613

ISSN: 1923-3299

Article DOI: $10.5663 / a p s . v 112.9613$

aboriginal policy studies is an online, peer-reviewed and multidisciplinary journal that publishes original, scholarly, and policy-relevant research on issues relevant to Métis, non-status Indians and urban Aboriginal people in Canada. For more information, please contact us at apsjournal@ualberta.ca or visit our website at

www.ualberta.ca/NATIVESTUDIES/aps/

or

http://ejournals.library.ualberta.ca/index.php/aps/ 


\title{
Seeing Like a Circle: Perspectives on the Field from a Dialogue on Urban Aboriginal Economic Development
}

\author{
Charles L. Horn, University of Victoria \\ and \\ Greg Halseth, University of Northern British Columbia
}

\begin{abstract}
Since the early 1970s, Aboriginal communities, policy analysts, and researchers have constructed "urban Aboriginal economic development" as both a domain of strategic intervention and a field of tactical contestation. An integral part of this project has been the creation of a body of academic knowledge about urban Aboriginal peoples and their relationship to the economy. This article surveys the current state of knowledge about urban Aboriginal economic development, identifying strengths and gaps in our understanding of this topic, arguing that unlike the policy and program domains, academic knowledge is characterized by its refracted, indirect nature. The analysis is informed by the results of a multi-year dialogue process on urban economic development between Aboriginal peoples, researchers, and policy analysts. In response to the limitations identified in the existing literature, we suggest two supplemental approaches: place-based economics, and new regionalism.
\end{abstract}

What does the research literature tell us about economic development in urban Aboriginal communities? This article attempts to answer that question in detail, largely through an overview of the literature on the relationship between urban Aboriginal peoples and the economy, focussing on the period between the late 1960s and the present. But as it turns out, there is also a shorter answer to this question, which is that we don't know very much about the urban Aboriginal economy directly but we know lots about it indirectly.

aboriginal policy studies, Vol. 1, no. 2, 2011

ISSN: 1923-3299

www.ualberta.ca/NATIVESTUDIES/aps/ 
Put in Kantian terms, our review of the literature below argues that, when subjected to the analytic gaze, the urban Aboriginal economy as such becomes obscure as a "thing in itself," and appears knowable only in the light of other objects. It is as though when Aboriginal people enter into the urban setting, the labouring self and the subjectivities and social relations attached to the reproduction of material life lose any distinctive form and come into view only reluctantly, and even then largely in the reflected light of other practices, such as community mobilization or governmental intervention. It is as if the field of urban economic development can be seen by researchers only through its relationships to other domains of knowledge, leaving the field itself (as a set of internal relations) to be mapped by practitioners, community advocates, and governmental bodies with an interest in program interventions.

From the perspective of conventional academic research, this would seem to constitute a gap in our knowledge. And indeed it is, with the result that our survey of the literature below is a survey around, rather than directly of, the issue. But, in a point we touch on later, from the perspective of Indigenous research methodologies this could be seen as a strength. In favouring the articulation of relations over the identification of objects, the literature could be said to have implicitly internalized a key principle of Indigenous thought: that to know the social world is to know it through its interconnections, that relations matter more than things, and that research in Indigenous communities should valorize relationality over individuation (Atleo 2004; Deloria 1991; Kovach 2009).

Why and how we have arrived at this particular state in our understanding of urban Aboriginal economic development invites inquiry. A full discussion of the application of an Indigenous relational ontology to this field risks turning an article into a monograph, and so our goal here is more modest: to summarize the current state of knowledge on urban Aboriginal economic development and identify the limits and gaps in that field as it is currently constituted. In the process, we hope to also link in a provisional way "economic development" as a distinct problematic within urban Aboriginal communities to the domains of government policy and community practice and mobilization. We thus, reluctantly, set aside the larger question of Indigenous methodologies for another day, with the hope that our short discussion here might encourage more debate.

Before proceeding, we note that the reflections below are informed by the authors' participation in the Urban Aboriginal Economic Development 
Network. ${ }^{1}$ The Network was a three-year knowledge mobilization project designed to foster the exchange of knowledge and experience between practitioners, policy analysts, and researchers. The intent was to foster a more informed policy context, providing strategic direction to research, and developing capacity amongst practitioners to support economic development in urban communities (see Appendix A for a more detailed description of the dialogue processes sponsored by the Network). We were honoured by the opportunity to hear the voices of people who care about this issue and who gave of their time and energy to the process. The analysis here remains our responsibility.

In this paper we focus not on the activities sponsored by the Network, but on describing the main features of the research knowledge available to participants in Network activities or others involved in the policy and practice of economic development in urban Aboriginal communities.

In undertaking this analysis, we are participating in the creation of the very thing we are talking about, not just in the sense that discourses are constitutive, but in the specific sense that, starting in the mid-to-late 1970s, economic development has been constituted within discussion of urban Aboriginal policy simultaneously in three dimensions: as an opportunity for political mobilization, as a distinct domain of governmental intervention, and as a problematic worthy of the (refracted) analytic gaze. The effect of these three dimensions over time, we suggest, has been to constitute urban Aboriginal economic development as an object around which a cluster of political and governmental projects could be organized and legitimated, and bodies of knowledge generated.

Thus, by the time the Urban Aboriginal Economic Development Network convened its first National Gathering in 2008, participants had available to them a developed body of policy and practice to draw from in articulating their experiences. This both provided a vocabulary to connect the economic domain to other aspects of urban Aboriginal life, and legitimate the mobilization and program intervention techniques central to the worlds of practice and policy.

A different picture emerges, though, when we focus on urban Aboriginal economic development as an academic sub-discipline. Here the outlines of 'the urban Aboriginal economy' as such are less distinct: perhaps because of its imbrication with programmatic interventions and political mobilization, the research field is constituted less by the creation of a distinct object or domain (Latour and Woolgar 1986), and more by its 
capacity to draw research from other areas (demographics, cultural studies, organizational analyses, etc.) and deploy these into domains constituted by practice or policy. In a sense, researchers constitute the field not by illuminating its interior-its unique mechanisms, constellation of forces, or agents - but by marking its dependency on, contrast with, or relationships to other fields. ${ }^{2}$ In the process of drawing from other bodies of thought circulating within Aboriginal communities, the urban Aboriginal economy as such has become invested in issues outside of economic development proper, such as the anxieties of acculturation (Alfred 2005), the promise of autonomy from dependency (Helin 2006), and the gradual strengthening of the community as a whole (Silver and Hay 2006). Let us turn to this literature now, starting with the attempt to discern an urban dimension to Aboriginal collective life.

\section{The Specificity of the Urban}

We can distinguish, in the early writings on urban Aboriginal peoples, two key strategies with respect to economic development that have proven decisive over time. First, starting about the time of the Hawthorn Report in 1966, the implicit project of research was to translate the intricate relationship between Aboriginal people and the reproduction of material life into the limited (and ultimately programmatic) question of how to manage the challenges of integration into non-Aboriginal labour markets (Hawthorn and Indian Affairs Branch 1966). The urban Aboriginal economy as such was, in these earlier works, not a distinct object, even though, in the Hawthorne Report, the recommended strategy for on-reserve economic development was essentially to send people into urban centres. In writings dominated by the problematic of labour market integration, the relationship between Aboriginal people in urban areas and the subjectivities and social relations associated with Aboriginal economic activities disappeared from view, as though the labouring self had been left behind when they moved into town. What appeared in its place was a picture of Aboriginal people as confronted with a set of (capitalist) social forces to which they were expected to accommodate, with the role of research being to provide empirical assessments of the "success or failure" of this project (Stanbury and Siegel 1975; Helin 2006). ${ }^{3}$ While individuals could occupy a position relative to the flows of capital, the activities of business enterprises, or the creation of goods and services (which was, overwhelmingly, seen as 
a position of marginalization), they remained in a position of exteriority to those forces, and without apparent agency to respond effectively to the dynamics of the non-Aboriginal economy. While we could unpack this perspective in more detail, the assimilationist thrust of the earlier literature is well known and need not detain us here. What is relevant for our purposes is that in reading the issue of the Aboriginal economy in this way, research cast the question of the urban Aboriginal economy as one that supported, even demanded, programmatic intervention. In this it took up the position, still available in the current literature, of providing research and empirical support for the governmentalization of the community; that is, the project of reorganizing the political and social relationships amongst community members, and between community members and external institutions (Rose 1990; Andersen 1999; Hannah-Moffat 2000).

Of more lasting impact, however, was the second feature of the early literature, which was to distinguish "urban Aboriginal" as a specific social space within the city. Acting as a supplement to received understandings of both urbanity and Aboriginality, the "urban Indian" (in the language of the time) was constituted not just as a person but also as a discrete set of social, cultural, and political relationships acting within a specifically urban space. In part, this was a response to the marked difficulties facing Aboriginal people as they moved to urban centres in the post-war era, but it also arose as a consequence of the disciplinary allegiances of the authors, who typically came from urban sociology (Dosman 1972), anthropology (Brody 1971; Ryan 1978), immigrations studies (Wilkes 2003), or urban studies (Nagler 1970; Waddell and Watson 1971; Guillemin 1975), disciplines that had carved out a well established space for dynamics and social relations that were specifically urban. ${ }^{4}$

But this emphasis on the specificity of the urban in these disciplines had a striking implication with respect to understanding Aboriginal peoples, for as far as the colonial imaginary was concerned, Aboriginal peoples were paradoxically most obviously Aboriginal when set within and against urban space, for unlike other immigrants to the city, they were marked simultaneously by their unexpected presence in urban areas and their estrangement from it. The result was to carve out a distinct domain of the urban for Aboriginal peoples, even if, for some, that domain was a site for the eventual disappearance of the peoples who moved within it. ${ }^{5}$ Despite significant advances, this foundational and paradoxical recognition of Aboriginal people in urban areas as "in the city but not of it" still shapes 
our understanding of urban Aboriginal economic development. While the "otherness" of the city's Aboriginal inhabitants is apparently intensified by being set against the backdrop of the urban, this intensification was read as producing not cultural strength, but political vulnerability. In so doing it marks the continued influence of the dominant perspective in Aboriginal policy and research: that Aboriginal communities and peoples are fully legible only when connected to the rural - witness the continued legal and political power of the phrase "ordinarily resident on reserve." 6

The assumptions that underlay this earlier literature, of course, do not withstand serious scrutiny. Wilson and Peters (2005) have argued, for instance, that the focus on land-based communities is a reflection of a colonial geography, not an Aboriginal one, a focus rendered possible because of the systematic exclusion of the "outside" of land-based communities. It bears noting that the early literature not only adopts the colonizer's political geography, but also adheres to the contours of capital. Property rights, the disciplines of time and industrial production, territorial control, governance understood as the process for setting rules for commercial/legal transactions, and the allocation and disposition of natural resources, to some extent, remain the dominant motifs of Aboriginal policy discourse.

But, despite its limitations, this first wave of research on Aboriginal peoples in urban centres did accomplish some important analytic work. When the critique of the literature discussed above is taken into account, what remains of value from this early literature is the recognition that urban Aboriginal economic development must be understood in its urban specificity, as a distinct field within which governmental action and social mobilization might occur. ${ }^{7}$ But, it remains true that urban economic development has not entirely escaped from the frameworks used to understand development in land-based communities (Mendelson 2004). So with others, we reiterate the need for an approach that responds directly to the dynamics, issues, realities, and potential present in urban communities (Foley 2008).

\section{Numbers Matter: Socio-demographic Analyses}

One of the consequences of distinguishing the urban as a space with a specific Aboriginal dimension, and of articulating the "economy" as a field of programmatic intervention, was that it became natural to specify with greater and greater precision the characteristics of the people who occupied 
that space and were the subjects of the intervention. Here we see a theme that has emerged as central to the literature on urban Aboriginal people: socio-demographic analyses. It is now ubiquitous to start discussions of urban Aboriginal issues with recitations of demographic facts. ${ }^{8}$ On this point, it is clear that the contribution of the research and policy community has been substantial. Both government and university researchers have produced a wealth of data and analysis, giving us detailed descriptions of the Aboriginal population in urban areas. This work has produced analyses of a number of aspects of urban Aboriginal life: residency patterns (Clatworthy 2000; Maxim, Keane et al. 2003), income levels, movement between urban and home communities (Norris, Cooke et al. 2003), class composition, age and gender distribution, population growth over time, employment patterns, and changes in Aboriginal identification over time and across locations (Newhouse, Peters et al. 2003; White, Maxim et al. 2003). More recently, we have added a qualitative dimension arising from the results of the 2010 Urban Aboriginal Peoples Study, which has given us insights into the cultural, political and social activities, and perspectives of urban Aboriginal peoples (Environics Institute 2010). This population level work has been supplemented by more descriptive analyses of particular urban communities, such as Seattle (Thrush 2007), Saskatoon (Dosman 1972), Winnipeg (Silver and Hay 2006), Chicago (Beck 2002; LaGrand 2002), Toronto (Nagler 1970; Proulx 2003), and others.

\section{Organizations Matter: Institutional Analyses}

A second area of contribution by the research community has been to point out the unique role played by Aboriginal organizations. In earlier works, such organizations as Friendship Centres were read mainly as conduits to enable individuals to "adjust" - that is, integrate into urban labour markets - and Aboriginal organizations were interpreted as assuming the role of a buffer between formal systems and community members. Reeves and Frideres, for instance, in their 1981 analysis of urban Aboriginal organizations, suggest that the effect of such organizations was less to mobilize Aboriginal peoplefor "natives lacked an elite who could mobilize [the community]" - and more to "provide a force which encourages the migration of natives into . . . the urban economy" (Reeves and Frideres 1981, 584). But, as recent work by Proulx and others shows us, urban organizations are also potent sites for 
social mobilization and community building (Weibel-Orlando 1991; Proulx 2003; Silver and Hay 2006). Further, because of their intimate knowledge of the community and its members, urban Aboriginal organizations were understood to be more effective at program interventions than governments, a point reinforced by countless university-based evaluations, reports, and commentary. Given the dominant role accorded to programmatic responses to the economic dislocation of Aboriginal peoples in urban centres, this articulation of the role of Aboriginal organizations was decisive in framing the urban organizations as central to the governmental response to meeting the material needs of Aboriginal community members.

We can also add to our institutional analysis the influence of the Harvard Project, which has been instrumental in bringing institutions of governance back into academic and popular analysis, confirming the need to address the structuring influence of Aboriginal institutions of governance and service delivery on economic development (Cornell 2006). In response to some of the anxieties that accompany the assimilationist tendencies of capitalist social relations, Newhouse has shown how Aboriginal organizations can operate within a framework of cultural practices while still meeting their mandate to provide contracted services to government (McCaskill, Newhouse et al. 1996; Newhouse 2001; Newhouse 2003). Newhouse's work supplements that done by Bellefeuille et al. (1997) on transformative practices in Aboriginal organizations, and Weibel-Orlando's analysis of how Aboriginal organizations in Los Angeles generate collective identity and enable collective action, even in the face of institutional crises (WeibelOrlando 1991). With respect to economic development, Peters (1996; 2005) and others have pointed out that the steady growth in size and complexity of urban organizations has created employment opportunities for an emerging professional class of Aboriginal people, in addition to generating skill sets and experiences that can be used in the pursuit of entrepreneurial goals (Wotherspoon, 2003).

This reading of Aboriginal organizations as possessing constitutive force also marks an important ontological shift. No longer was the issue simply one of attaching individuals to the labour force, as it was in earlier analyses; rather, through the process of institutional development, urban Aboriginal people began to assume the capacity to act as a collective even as it became clear that urban Aboriginal organizations were not co-extensive with the community in any relevant sense (notwithstanding their claims to the contrary). This marks, in Gramscian terms, a shift to negotiating the 
relationship to the forces of the capitalist economy at the level of strategy, not just tactics.

The conclusion from these analyses is that for urban Aboriginal economic development, institutions matter (National Association of Friendship Centres 2009; Papillon and Cosentino 2004). Precisely how they matter remains an open question, except that we now know that they operate not as independent spheres, but rather in their relationships to other spheres of life, such as the cultural, the social, and the political. We also know that for community members, urban Aboriginal organizations, despite their well known limitations, play an important advocacy and interest articulation role, as well as providing a mechanism for support, cultural and otherwise, for some early stage entrepreneurs (Silver and Hay 2006).

\section{Policy Matters}

If, as we have suggested, governmental intervention was one of the key structuring forces in constituting the field within which Aboriginal people conducted their relationship to the economy, then this necessarily draws our attention to the role of government policy. Here the results are less than hopeful, for by and large this work shows us that Aboriginal entrepreneurs, organizations, and communities still face an unsupportive and uncoordinated policy context (Hanselmann 2001; Newhouse, Peters et al. 2003). Put another way, while the state has decisively influenced the strategies available to community members to manage the reproduction of material life, it has done so in a partial, incomplete, and in some cases incoherent way (Weaver 1981; Stokes, Peach et al. 2004). In part, this literature has helped us see that this ineffectiveness arises because government policy is conditioned by assumptions and issues drawn from First Nations communities or, alternatively, from generic urban policy (Anderson, Breton et al. 1984; Abele and Graham 1990). While this literature has not focused particularly on the case of economic development, it has given us solid a snapshot of the policy field (Surtees 1982) and a clear sense that the field needs to be rethought if it is to be useful for urban Aboriginal communities (Hanselmann 2002). 


\section{Land Based and Urban: Circuits Matter}

Earlier, we noted that an understanding of urban Aboriginal economic development required careful attention to its geography, and the specific dynamics of the urban setting in particular. Here, however, we want to complicate this requirement with the recognition that urban centres are not enclaves any more than reserves are. We should be alert to the ways in which urban centres act as managers of flows - of goods, services, materials, and people-from elsewhere (Lefebvre 1991), and that the "elsewhere" is, in turn, marked by its relationship to urban circuits and dynamics. This is, of course, an old insight into the circuits and flows of capital in urban centres; what is new here is the (still underdeveloped) recognition that there is a specifically Aboriginal circuit that both mimics and supplements the existing flows and movement of capital, goods, and people in local and regionaland, to a lesser extent, national and global-economies (Levesque 2003). Loxley and Wien, for instance, in their summary of urban Aboriginal economic development for the anthology Not Strangers in These Parts, make precisely this point in their efforts to identity strategies for effective economic development for Aboriginal communities. The point is also echoed by Wuttanee (2004), and in the context of cultural transmission by Weibel-Orlando (1991), reminding us that what we are examining, rather, are the flows between different centres of production, distribution, and consumption, each conditioned by its own internal dynamics, its distinct position in the larger (global) economy, and the relative power and capacity of the relevant actors in each location.

Distinguishing an urban Aboriginal space; socio-demographic analysis; community specific assessments; the logic of program interventions; the role of Aboriginal organizations; and urban-rural relationships: these are some of the contributions of the existing literature on urban Aboriginal economic development. Even if, as we have suggested, the "urban Aboriginal economy" as such has not yet emerged in its interiority within the research community, the literature has made a contribution to the capacity of practitioners and policy analysts to engage in productive and informed discussions. Participants in the dialogue processes supported by the Network made use of these insights in their discussions, and the analyses in the existing literature have obvious resonances within communities and in government offices. 


\section{Limits and Gaps: What We Don't Know}

Yet, it is fair to say that in its efforts to constitute itself as an autonomous field, research on urban Aboriginal economic development has encountered a series of limitations, derived in part from its attachments to other areas of inquiry, and from its internal limitations. These include the following points.

\section{Organizational Landscape}

We remarked above that, despite the ambivalence about the capacity of urban Aboriginal organizations to effectively negotiate the terms of Aboriginal participation in the economy, they were seen in the literature as having a central role. This is, in part, because of the influence of the Harvard Project, which accords a significant role for tribal institutions. But we know that urban groups cannot perform the rule setting and enforcement role ascribed to Indian tribes by the Harvard Project, having neither the formal-legal capacity nor the control over a territory needed for that role (e.g., Jorgensen and Taylor 2000). Moreover, urban Aboriginal communities do not typically have a clear mechanism for articulating priorities or preferences for economic development, nor indeed the limited but still real access to capital or investment partners that are available to at least some First Nations. We found that the majority of the institutional prescriptions of the Harvard Project for successful economic development did not translate well into an urban context, in large part because the very different political and legal position of urban communities and community organizations. But, in setting aside the Harvard Project, we were faced with the recognition that we have little hard evidence about the actual relationship between economic development and the activities of Aboriginal organizations in urban settings. In the Learning Circles that were the core part of the Urban Aboriginal Economic Development Network, some participants suggested to us that urban organizations provided important support to the activities of entrepreneurs and community activists. Others suggested, however, that Aboriginal organizations played little or no role in their efforts to build a business, and in fact sometimes got in the way. Faced with these different interpretations of the role of Aboriginal organizations, some empirical evidence would be helpful, but the current research literature does not present a well-developed, systematic, transferable understanding of what 
impact organizations have on economic activities. Nor does it show how community members "draw down" organizational resources, or how the network of Aboriginal organizations creates a climate that supports (or fails to support) community members in their attempts to gain access to, modify, or evade the larger economy. The analysis of urban organizations tends to remain at the descriptive level (e.g., Sawchuck 2001), focusing largely either on their internal arrangements (e.g., Webiel-Orlando 1991) or on their cultural capacity (e.g., Redpath and Nielsen 1997; Newhouse and Chapman 1996; Chapman, McCaskin et al 1991), and as a result often lack empirical depth with respect to how organizations respond to the needs of Aboriginal entrepreneurs or to the economy at large (but see Proulx 2003). ${ }^{9}$

More seriously, the literature has not examined in any rigorous way the limitations imposed by the dominance of service delivery modalities in urban organizational life, and the way that the instrumentalities of service provision and government funding structure the field of economic and social action. For instance, it has been noted that the social service orientation of most urban organizations makes it problematic for middle-class urban Aboriginal people to participate in community affairs, which are typically managed or organized by urban organizations (Urban Aboriginal Task Force, 2007). Given the centrality of the middle class to most histories of economic development, this should warrant more scrutiny, yet the literature remains relatively silent on it. ${ }^{10}$ Nor has consideration been given to questions of whether organizations have any capacity to act collectively in a way that would have real influence in the field of economic development policy. Their role remains unexplored.

\section{Socio-demographic Data}

Considerable energy has been expended in urban Aboriginal research on determining in greater and greater detail the demographic and social characteristics of the population, but much of this information had little perceived direct relevance to the practical challenges facing Aboriginal entrepreneurs, or the organizations that supported them. Viewed as a strategic resource, some pieces of information were useful, but these tended to be focused on the simple fact of an urban numerical majority, the strategic value of which was obvious to participants looking for ways to ensure a fair share of government funding resources. The policy relevance of the material is not always clear either; much of the analysis is too fine- 
grained to be of guidance to the broad strokes typical of the policy world and, in addition, is cast in language that is a considerable distance from the ways communities would describe themselves. As well, there is the critique that the quality of the data gathered on Aboriginal people in urban areas is potentially problematic, both in terms of its reliability and the adequacy of its classification schemes, in addition to the political challenge posed by First Nations political bodies to the data showing a majority of Aboriginal people are urban residents.

More troubling than this is the potential role of such data gathering in the govermentalization of Aboriginal communities. That is, the project of gathering socio-demographic data can also be understood as the project of enabling the state to organize, manage, and administer Aboriginal populations, both as a mechanism to control dissent and as a uniquely modern technology of governing (Foucault, Burchell et al. 1991). Faced with an Aboriginal community characterized by personal mobility and uncertain spatial boundaries, the socio-demographic project can be seen as a project of fixing a population so it can be better inserted into recognizable western scientific categories and administrative apparatuses. The current literature on this issue demonstrates a striking naiveté about the political implications of its research agenda.

The dense and ever accumulating body of socio-demographic data about Indigenous populations does mark a problematic, though, that is worth noting: that the story of urban communities is a story about beginnings, about how these are to be understood in an urban context, and about entries into and exits from the city and the reserve. It thus marks an anxiety, or at least an uncertainty, on the part of research and policy about political beginnings, understood as an emergence, and boundaries, understood as the movement between the space of the traditional territory and the space of the urban. Aboriginal people are now in the city (this much the sociodemographic literature accomplishes), but the issue of the specific ways in which Aboriginal people were of the city remains a problem for the analytical gaze. And so this literature responds by encapsulating or circumscribing Aboriginal community members within a rubric of population and demographic discourses.

\section{Transformative or Reformist?}

Underlying the literature on Aboriginal economic development-and on Aboriginal policy in general-is the assumption that there is something 
distinct about the relationship between Aboriginal communities and the economy, and that the distinctiveness at issue turns on the unique, persistent, features of Aboriginal communities. While there are prominent voices that suggest economic development is essentially assimilative (e.g., Alfred 2005), the literature is more accurately characterized as assuming Aboriginal people can engage in economic development without losing their identity as Aboriginal people. It follows from this that there is a role for research in assessing the ways in which Aboriginal peoples turn economic development activities into Aboriginal activities. In the Learning Circle dialogues that were part of the Urban Aboriginal Economic Development Network, participants made frequent reference to the role of the broader community, the obligations of community members, the relationship between urban and rural Aboriginal communities, and the usefulness of cultural supports to strengthen the capacity of early stage Aboriginal entrepreneurs. In doing so, participants were gesturing to the culturally specific ways in which Aboriginal people engage in business and economic activities. But, behind these comments, looms a larger question, inadequately considered in the literature, about the purpose and social effects of Aboriginal economic development (Anderson, Peredo et al. 2007). Is the goal simply a redistribution of the surplus value accrued from the operations of the capitalist economy? Or, to use Loxley's distinctions, is Aboriginal economic development transformative in intent, having as its goal changing the social relations typical of capitalism into something recognizably Aboriginal (Loxley 2002)? Here we echo the issues raised in the Royal Commission on Aboriginal Peoples: does economic development support communities, not just individuals? Put more bluntly, how do we ensure that economic development does not just become another mechanism to encourage the assimilation of Aboriginal peoples into the capitalist mainstream (RCAP, 1996)? The discussions at the Learning Circles and elsewhere in the Urban Aboriginal Economic Development Network indicate that what we were witnessing was an attempt to "map" an Aboriginal specific way of living in community and culture onto the circuits and modalities of the mainstream economy. In other words, urban Aboriginal economic development is not just about encouraging capitalist acts between consenting Aboriginal adults, but is also, and perhaps more fundamentally, about positioning business activities in the context of Aboriginal communities, cultures and identities. Such indications could benefit from a closer examination of the effects of economic development on communities, where an examination would 
include but also go beyond the now familiar story about the destructive and assimilationist effects of, say, natural resource development on communities. Critics such as Alfred (1999), for instance, have criticized economic development as deeply reformist-indeed, assimilationist-in character. This critique is in part a political one, but it is also in part an empirical claim, and the literature has not taken up the challenge to determine the accuracy of this critique in complex and varied urban communities. Writ large, this particular debate is essentially the debate about the terms under which Aboriginal people can engage with the form and content of Western modernity, with capitalism as both the exemplar of the forces of modernity and the necessary condition of engagement in the first place. What is needed is a better analysis of how Aboriginal people "Indigenize" the economy or, alternatively, fail to do so through their actions and their relationships, analyses which take seriously Aboriginal people as active agents in the world, but also accounts for the dynamics of the economy (Anderson and Giberson 2004; Wuttunee 2004).

\section{Integrated Worlds: Holism Matters}

Despite the influence of the Harvard Project, which implied the need for a relational and holistic approach to economic development, the literature on urban Aboriginal peoples seems reluctant to develop a "thick description"of the kind Geertz imagined - of the actual relationships between economic activities and the cultural, political, and social domains of urban community life (Geertz 1973; Hanselmann 2002). This lack of empirical insight is not for lack of awareness of the importance of these interrelationships; the literature frequently gestures in the direction of a holistic approach and, occasionally, even offers us glimpses of these relationships. Berman (2003), for instance, writing in an on-reserve context about Aboriginal women, describes the "ceremonial relations of production" she observed, by which she means the complex interrelationships Aboriginal women enact between their business activities and the cultural life of the community, the subsistence economy, and the market economy. Our own experience in the Learning Circles associated with the Urban Aboriginal Economic Development Network reinforced this perspective: participants frequently referenced the intricate connections between their business activities and the other dimensions of their lives. But, despite their importance as a reference point for Aboriginal communities, we lack a solid analysis 
of how these inter-relationships play out in urban settings. ${ }^{11}$ This gap is particularly interesting given that practice of service delivery in Aboriginal communities has long focused on the importance of interrelationships to the task of building the personal capacity of community members, on the principle that programmatic interventions are effective only when they address the multiple dimensions (social, cultural, mental, and physical) of a client's life. It may be that the failure to take this point seriously arises from the individuating and disaggregating assumptions of Western science that underlie much of current social science research. In any event, the outcome is to limit the effectiveness of our analysis and the policies that flow from it. Here, we are once again reminded of an emerging thematic of the literature on the urban: that significant dimensions of the lives of Aboriginal people are rendered invisible from the analytic gaze when they are played out in urban settings. Or, perhaps more precisely, they become unloosed from the categories and frameworks that have been established to articulate the challenge Aboriginal peoples pose to the colonial state, and so cannot be captured in any easy way by academic writings about the urban.

There is a second dimension to this call for holism, which is to insist that research, policy, and practice ought to speak to the whole of the community: elders, children, and the working age population. Again, such an approach takes into account what we know about the development of Aboriginal communities and the relationship between members and their community: a healthy integrated community is an important source of support for the activities of its members, including the activities of entrepreneurs.

There remains, though, the point we made in the introduction, where we suggested that the lack of a "centre," if you will, for research on the urban Aboriginal economy could be read not so much as a limitation or a blindness, but rather as an implicit reflection of the principle of holism according to which we can understand an object only (or best) by understanding it in its relations to other objects or beings. So the fact that the research community understands the urban Aboriginal economy not directly but only through its relationships to other bodies of knowledge (demography, neoinstitutionalism, policy studies, etc.) may well be-from the perspective of an Indigenous ontology - precisely the right way to approach the field (Stewart-Harawira 2005). If this is the case, then it would makes sense for the discipline of urban Aboriginal studies to make this principle explicit and use it to explore the potential for meaning making and knowledge creation 
that such an approach might present (Deloria 1999). And it remains the case that even this (generous) interpretation cannot rescue the literature from its failure to successfully integrate the various bodies of thought it draws from into a unified, coherent, and distinct whole.

\section{Place-Based Economies and New Regionalism}

Above, we considered some of the limitations of the existing state of knowledge about urban economic development. In this section, we turn to some possible alternative ways of thinking about this issue. As a way of broadening the influences in the field, we draw on literature that is not normally cited in studies of urban Aboriginal economic development; in particular, on new regionalism and studies of place-based economies.

The motivation behind turning to these fields is recognition of the contributions of researchers interested in a territorial and locational understanding of economic activity. New regionalism for instance, shows us that social and economic processes never work themselves out the same in all places due to unique local histories and attributes, and has the advantage, from the perspective of Aboriginal economic development, of encouraging a role for state institutions in supporting local organizations to assume a role in responding to more global economic processes (Brenner and Theodore 2002; Young and Mathews 2006). Those global processes both engage with the local, but are also changed by that engagement. For our purposes, this literature also has the benefit that it takes urban centres seriously (Markey, 2008).

Some of writings on new regionalism, perhaps even most of them, can be read as responses to globalization, resulting in an undue emphasis on the post-Fordist regimes of accumulation that produce flexible capitalism and the importance of locales associated with this form of accumulation (Jessop 1994; Stewart-Harawira 2005).

When we engaged with Aboriginal communities and entrepreneurs in the Urban Aboriginal Economic Development Network, we heard of the importance of local communities, and of how economic development for Aboriginal peoples was inseparable from very specific local and the regional contexts. For Aboriginal peoples, a focus on the local cannot be read simply as a response to the global, as it often is for mainstream community economic development, although criticisms of the impact of globalization on Aboriginal communities are easy enough to find (see, e.g., 
Alfred 2005; Stewart-Harawira 2005). Rather, what we heard, sometimes implicitly, sometimes explicitly, was the importance of social networks in the community, not the impact of the global on daily life. No doubt the global has crept into the local in urban Aboriginal communities, but our engagement with practitioners and communities through the Network indicated that this was not the key issue when it came time to talk about the specifics of place, and the potential forces impacting particular communities. Thus, while this literature bespeaks a preoccupation with the effects of globalization that does not resonate in Aboriginal communities, we think we can still take away the central lesson: that economic development is powerfully shaped not just by space-or even the compression of space-time-but also place. New regionalism can potentially provide the tools needed to understood "the community" not just as an actual existing locality or local economy, but also as a social, cultural, and economic space created or defined by communities and their members (Williams and Stewart 1998; Wilson and Peters 2005).

Earlier, we noted that one distinctive feature of urban Aboriginal economic development was the intricate relationship between urban and First Nations or Métis communities. As discussed above, Aboriginal community members who participated in Network Learning Circle activities often referenced their connections or relationships to First Nations, indicating the presence of a distinct Aboriginal economic geography. It is not simply that goods, services, skills, people, et cetera, move between urban centres and their reserves, or that urban and land-based economic activities are intertwined. It is rather that the distinct spatial patterns that emerge from the relationships between urban and land-based communities are an important, if under-recognized, mechanism for "Indigenizing" the economy, in that such spatial patterns are based on distinctly Indigenous identities, values, and relationships (i.e., to one's First Nation, or to a territory). If urban Aboriginal economic development is to be understood as place-based, then it must be understood not as a location, or a container, but as a relationship to place that is specifically Aboriginal. The development of an Aboriginal economy is not simply a response "from below" to globalization, nor simply the development of business or economic networks aimed at controlling or redirecting economic benefits. It is, we suggest, an attempt to create a distinctly Indigenous set of economic relationships that reflects and mobilizes relationships between Indigenous peoples and their communities. This attempt has a distinctively Aboriginal spatial dimension to it, and that 
spatial dimension is organized around Aboriginal understandings of place. It is for this reason that we cite studies of place based economics as a potential source of insight into urban Aboriginal economic development (Markey, Halseth, et al. 2008a; 2008b).

\section{Summary and Conclusion}

The stakes for our understanding of urban Aboriginal economic development are high. They most certainly include the driving question of enabling urban Aboriginal communities to participate as equals in the economy, with all the potential gains of getting it right and the consequences of getting it wrong. But, they also include the issue of changing the overall approach to Aboriginal issues in Canada with the goal of ensuring a more balanced perspective, one that takes seriously the permanent presence of Aboriginal people in urban centres. Researchers have a role to play in this goal, and this paper has been an attempt to articulate the strengths and weaknesses of our current understandings.

There is, however, more at stake for the academic community. The presence of urban Aboriginal communities challenges us to rethink in more fundamental ways the categories, concepts, and ideas we have used to engage with Aboriginal peoples. The current language too easily leads to either seeing urban communities as incomplete, and thus sites of loss, or alternatively to cast communities into a model that reflects non-Aboriginal needs and wants, or the unique social, economic, and political circumstances of land-based Aboriginal communities. As well, it may be that such a reexamination also leads us to question fundamental categories in play in the social sciences, and thus push us to a more profound reassessment of the field.

\section{Endnotes}

1. The authors gratefully acknowledge the support of the Social Sciences and Humanities Research Council and Indian and Northern Affairs Canada for financial and technical support for this project.

2. Echoing here the questions asked by Hindle and Landsdowne, "What are the boundaries of the field? What should be studied within it?" "Brave 
Spirits on new Paths: Towards a Globally Relevant Paradigm for Indigenous Entrepreneurship Research." In International Handbook of Research on Indigenous Entrepreneurship, Eds., Leo-Paul Dana and Robert Anderson, Edward Elgar Publishing, Cheltenham, UK: 2007.

3. An orientation that is today echoed, without any obvious sense of historic irony, in the insistent demand that research lay bare the conditions for success or failure of Aboriginal business enterprises. Compare Stanbury and Siegel (1975) with Helin (2006).

4. In contrast, Peter Morris suggests that in an Australian context the literature on urban economic development is dominated by business professors (Morris 2003).

5. To be sure, these analyses were used in the main to locate and ground a critique of government policy, and so should be read with a sympathetic ear to their intent.

6. We note there have been challenges to the claim that the urban represents a specific space for Aboriginal peoples. See e.g., R. Darnell, R. and M. Munguia (2005). Nomadic Legacies: an Urban Algonquin Residence. In Papers of the Thirty-Sixth Algonquian Conference. H. C. Wolfart, Ed. Winnipeg, MB., University of Manitoba: 173-86. Newhouse describes this propensity to see Aboriginal people as essentially rural as the continued legacy of the urban-folk continuum, with Aboriginal people as decidedly folk, not urban (1999:247).

7. Our focus on the specificity of the urban in economic development is supported by works on the geography of capital. While the resource extraction activities of land-based communities operate within the fixed spatial domain of the territory and, more narrowly, the reserve, the space of the urban economy differs in being more aligned with what David Harvey calls a 'relative spatiality': the movement of capital, exchange values, shifting bases of production, etc. (Harvey 1985; Harvey 2001).

8. In her analysis of an economic development project in Winnipeg, Wanda Wuttunee remarks "Statistics formed the basis of the early discussions.," 
and goes on to quote an interviewee: "We didn't want to start with the issues so we looked at some of the statistics ..."(Wuttunee 2004: 58).

9. A point echoed by David Newhouse in 1999: "This network of [urban Aboriginal] organizations has been neglected in the research literature on Aboriginal peoples ..." (Newhouse, 1999: 244).

10. See however (Wotherspoon 2003).

11. There is an important exception to this rule. In the course of describing the life course of individuals moving into urban settings we are often told about how social and familial connections are used to connect new arrivals to the city to the labour force (e.g., Guillemin 1975).

\section{References}

Abele, F. and K. Graham. 1989. "High Politics Is Not Enough: Policies and Programs for Aboriginal Peoples in Alberta and Ontario." In Aboriginal Peoples and Government Responsibility: Exploring Federal and Provincial Roles. D. C. Hawkes, Ed. Montreal, McGillQueens University Press: 141-171.

Alfred, T. 1999. Peace, Power, Righteousness: An Indigenous Manifesto. Don Mills, ON: Oxford University Press.

Alfred, T. 2005. Wasáse: Indigenous Pathways of Action and Freedom. Peterborough, ON: Broadview Press.

Andersen, C. 1999. "Governing Aboriginal Justice in Canada: Constructing Responsible Individuals and Communities Through 'Tradition.'” Crime, Law and Social Change 31 (4): 303-26. http://dx.doi.org/10.1023/A:1008372610195

Anderson, D. L., R. Breton, et al. 1984. The Dynamics of Government Programs for Urban Indians in the Prairie Provinces. Montreal: Institute for Research on Public Policy. 
Anderson, R. B., and R. Giberson. 2004. “Aboriginal Entrepreneurship and Economic Development in Canada: Thoughts on Current Theory and Practice." In Ethnic Entrepreneurship: Structure and Process, eds., C. Stiles and C. S. Galbraith. Oxford, Elsevier/JAI Publishing, 4: 141-170.

Anderson,R.B.,A.M.Peredo, et al.2007."The Saskatchewan Experience.” In International Handbook Of Research On Indigenous

Entrepreneurship, eds., L.-P. Dana and R. B. Anderson, 352-89. Cheltenham, UK: Edward Elgar.

Atleo, Richard (Umeek). 2004. Tsawalk : A Nuu-chah-nulth Worldview. Vancouver: UBC Press.

Beck, D. 2002. "Developing a Voice: The Evolution of Self-Determination in an Urban Indian Community." Wicazo Sa Review 17 (2): 117-41. http://dx.doi.org/10.1353/wic.2002.0014

Bellefeuille, G., S. Garrioch, et al. 1997. Breaking the Rules : Transforming Governance in Social Services. Thompson, MB: Awasis Agency of Northern Manitoba.

Berman, T. L. 2003. Circle of Goods: Women, Work, and Welfare in a Reservation Community. Albany: State University of New York Press.

Brenner, N. and N. Theodore. 2002. "Preface: From the New Localism to the Spaces of Neo-liberalism.” Antipode 34: 341-47.

Brody, H. 1971. Indians on Skid Row. Ottawa: Northern Science Research Group, Dept. of Indian Affairs and Northern Development. http://dx.doi.org/10.1111/1467-8330.00245

Chapman, I., D. McCaskill, et al. 1991. "Management in Contemporary Aboriginal Organizations." The Canadian Journal of Native Studies 11 (2): 333-49. 
Clatworthy, S. J. 2000. Factors Influencing the Migration of Registered Indians Between On and Off-Reserve Locations in Canada. Ottawa: Research and Analysis Directorate, Indian and Northern Affairs Canada.

Clement, W. and L. F. Vosko, eds. 2003. Changing Canada: Political Economy as Transformation. Montreal and Kingston: McGillQueen's University Press.

Cornell, S. 2006. Indigenous Peoples, Poverty and Self-Determination in Australia, New Zealand, Canada and the United States. Cambridge, MA: The Harvard Project on American Indian Economic Development.

Darnell, R. and M. Munguia. 2005. "Nomadic Legacies: An Urban Algonquin Residence." Papers of the Thirty-Sixth Algonquian Conference, ed. H. C. Wolfart, 173-86. Winnipeg: University of Manitoba.

Deloria, V., Jr. 1999. Spirit and Reason: The Vine Deloria Reader. Golden, CO: Fulcrum Publishing.

Dosman, E. J. 1972. Indians: The Urban Dilemma. Toronto: McClelland and Stewart.

Environics Institute. 2010. Urban Aboriginal Peoples Study: Main Report. Toronto: Environics Institute.

Foley, D. 2008. “Does Culture and Social Capital Impact on the Networking Attributes of Indigenous Entrepreneurs?" Journal of Enterprising Communities 2 (3): 204-24. http://dx.doi.org/10.1108/17506200810897204

Foucault, M., G. Burchell, et al. 1991. The Foucault Effect: Studies in Governmentality: with two lectures by and an interview with Michel Foucault. Chicago: University of Chicago Press. 
Geertz, C. 1973. The Interpretation of Cultures: Selected Essays. New York: Basic Books.

Guillemin, J. 1975. Urban Renegades: The Cultural Strategy of American Indians. New York: Columbia University Press.

Halseth, G., R. Halseth, et al. 2004. Building for Success: Explorations of Rural Community and Rural Development. Brandon, MB: Rural Development Institute, Brandon University, and Canadian Rural Revitalization Foundation.

Halseth, G., S. Markey, et al., eds. 2010. The Next Rural Economies: Constructing Rural Place in a Global Economy. Oxfordshire, UK: Cabi Press.

Hannah-Moffat, K. 2000. "Prisons That Empower." British Journal of Criminology 40 (3): 510-31. http://dx.doi.org/10.1093/bjc/40.3.510

Hanselmann, C. 2001. Urban Aboriginal People in Western Canada: Realities and Policies. Calgary: Canada West Foundation.

Hanselmann, C. 2002. Uncommon Sense: Promising Practices in Urban Aboriginal Policy-Making and Programming. Calgary: Canada West Foundation.

Harvey, D. 1985. The Urbanization of Capital: Studies in the History and Theory of Capitalist Urbanization. Baltimore, MD: John Hopkins University Press.

Harvey, D. 2001. Spaces of Capital: Towards a Critical Geography. Edinburgh and New York: Edinburgh University Press.

Hawthorn, H. B. and Indian Affairs Branch. 1966. A Survey of the Contemporary Indians of Canada: A Report on Economic, Political, Educational Needs and Policies. Ottawa: Indian Affairs Branch.

Helin, C. 2006. Dances with Dependency: Indigenous Success Through Self-reliance.Vancouver:OrcaSpiritPublications\&Communications. 
Hindle, K. and M. Lansdowne. 2007."Brave Spirits on New Paths:

Towards a Globally Relevant Paradigm for Indigenous

Entrepreneurship Research.” In International Handbook of Research on Indigenous Entrepreneurship, eds. L.-P. Dana and R. Anderson, 8-20. Cheltenham: Edward Elgar Publishing.

Jorgensen, M. and J. Taylor. 2000. What Determines Indian Economic Success? Evidence from Tribal and Individual Indian Enterprises. Cambridge, MA: Harvard Project on American Indian Economic Development, Wiener Center for Social Policy, John F. Kennedy School of Government.

Jessop, B. (1994). "Post-Fordism and the State." In Post-Fordism: A Reader, ed. A. Amin, 251-79. Oxford, UK: Basil Blackwell. http://dx.doi.org/10.1002/9780470712726.ch8

LaGrand, J. B. 2002. Indian Metropolis: Native Americans in Chicago, 1945-75. Urbana: University of Illinois Press.

Latour, B. and S. Woolgar. 1986. Laboratory Life: The Construction of Scientific Facts. Princeton, NJ: Princeton University Press.

Lefebvre, H. 1991. The Production of Space. Oxford and Cambridge, MA: Blackwell.

Loxley, J. 2002. Aboriginal Economic Development in Winnipeg. Winnipeg: University of Manitoba.

Loxley, J. and F. Wien. 2003. "Urban Aboriginal Economic Development." In Not Strangers in These Parts: Urban Aboriginal Peoples, eds. D. Newhouse and E. J. Peters, 217-42. Ottawa: Policy Research Initiative.

Markey, S. (2005). "Building Local Development Institutions in the Hinterland: A Regulationist Perspective from British Columbia, Canada." International Journal of Urban and Regional Research 29 (2): 358-74. http://dx.doi.org/10.1111/j.1468-2427.2005.00589.x 
Markey, S. 2008. Addressing Poverty and Competitiveness through Placebased Development in Surrey, British Columbia. Surrey, BC: White Paper for the Surrey Regional Economic Summit organized by the City of Surrey and the Surrey Board of Trade.

Markey, S., G. Halseth, et al. 2008a. "Closing the Implementation Gap: A Framework for Incorporating the Context of Place in Economic Development Planning." Local Environment: The International Journal of Justice and Sustainability 13 (4): 337-51. http://dx.doi.org/10.1080/13549830701803315

- - - 2008b. "Challenging the Inevitability of Rural Decline: Advancing the Policy of Place in Northern British Columbia." Journal of Rural Studies 24 (4): 409-21.

Maxim, P. S., C. Keane, et al. 2003. "Urban Residential Patterns of Aboriginal People in Canada." In Not Strangers in These Parts: Urban Aboriginal Peoples, eds. D. Newhouse and E. Peters, 79-91. Ottawa: Policy Research Institute.

Mendelson, M. 2004. Aboriginal People in Canada's Labour Market: Work and Unemployment, Today and Tomorrow. Caledon Institute of Social Policy.

Morris, P. 2003. “Aboriginal Economic Development in Urban Areas: A Framework for Comparative Analysis." Indigenous Nations Studies Journal 4 (1): 47-62.

Nagler, M. 1970. Indians in the City: A Study of the Urbanization of Indians in Toronto. Ottawa: The Canadian Research Centre for Anthropology, Saint Paul University.

National Association of Friendship Centres. 2009. Urban Aboriginal Economic Development: A Friendship Centre Perspective. Ottawa: NAFC. 
Newhouse, D. 2001. "Resistance is Futile: Aboriginal Peoples Meet the Borg of Capitalism." Journal of Aboriginal Economic Development 2(1).

- - . 2003. "The Invisible Infrastructure: Urban Aboriginal Institutions and Organizations." In Not Strangers in These Parts: Urban Aboriginal Peoples, eds. D. Newhouse and E. J. Peters, 243-55. Ottawa: Policy Research Initiative.

Newhouse, D., and E. J. Peters, eds. 2003. Not Strangers in These Parts: Urban Aboriginal Peoples. Ottawa: Policy Research Initiative.

Norris, M. J., M. Cooke, et al. 2003. “Aboriginal Mobility and Migration Patterns and the Policy Implications.” In Aboriginal Conditions: Research as Public Policy, eds. J. P. White, P. Maxim and D. Beavon, 108-30. Vancouver: UBC Press.

Papillon, M. and G. Cosentino. 2004. Lessons from Abroad: Towards a New Social Model for Canada's Aboriginal Peoples. Ottawa: Canadian Policy Research Network.

Peters, E. 1996. “'Urban' and 'Aboriginal': An Impossible Contradiction.” In City Lives and City Forms: Critical Research and Canadian Urbanism, eds. J. Caulfield and L. Peake, 7-62. Toronto: University of Toronto Press.

Peters, E. 2005. "Indigeneity and Marginalisation: Planning For and With Urban Aboriginal Communities in Canada." Progress in Planning 63 (4): 327-404. http://dx.doi.org/10.1016/j.progress.2005.03.008

Proulx, C. 2003. Reclaiming Aboriginal Justice, Identity, and Community. Saskatoon: Purich.

Redpath, L. and M. O. Nielsen. 1997. "A Comparison of Native Culture, Non-Native Culture and New Management Ideology." Canadian Journal of Administrative Sciences / Revue Canadienne des Sciences de l'Administration 14 (3): 327-39. 
Reeves, W. and J. Frideres. 1981. "Government Policy and Indian Urbanization: The Alberta Case." Canadian Public Policy/Analyse de Politiques 7 (4): 584-95. http://dx.doi.org/10.2307/3549488

Royal Commission on Aboriginal Peoples. 1996. "Chapter 5: Economic Development," in The Report of the Royal Commission on Aboriginal Peoples. Volume 2: Restructuring the Relatonship. Ottawa: Canada.

Rose, N. 1990. Governing the Soul: The Shaping of the Private Self. London: Routledge.

Ryan, J. 1978. Wall of Words: The Betrayal of the Urban Indian. Toronto: P. Martin Associates.

Silver, J. and J. Hay. 2006. In Their Own Voices: Building Urban Aboriginal Communities. Black Point, N.S.: Fernwood Publishers.

Stanbury, W. T. and J. H. Siegel. 1975. Success and Failure: Indians in Urban Society. Vancouver: UBC Press.

Stewart-Harawira, M. 2005. The New Imperial Order: Indigenous Resistance to Globalization. London: Zed Books.

Stokes, J., I. Peach, et al. 2004. Rethinking the Jurisdictional Divide: The Marginalization of Urban Aboriginal Communities and Federal Policy Responses. Regina: Institute for Public Policy.

Surtees, R. J. 1982. Canadian Indian Policy: A Critical Bibliography. Bloomington, IN: Published for the Newberry Library [by] Indiana University Press.

Thrush, C.-P. 2007. Native Seattle: Histories From the Crossing-over Place. Seattle: University of Washington Press.

Waddell, J. O. and M. Watson, eds. 1971. The American Indian in Urban Society. Little, Brown Series in Anthropology. Boston: Lttle Brown.

Weaver, S. 1981. Making Canadian Indian Policy: The Hidden Agenda, 
1968-1970. Toronto: Toronto University Press.

Weibel-Orlando, J. 1991. Indian Country, L.A.: Maintaining Ethnic Community in Complex Society. Urbana: University of Illinois Press.

White, J. P., P. S. Maxim, et al. 2003. Aboriginal Conditions: Research as a Foundation for Public Policy. Vancouver: UBC Press.

Wilkes, R. 2003. "The Residential Segregation of Native Americans in U.S. Metropolitan Areas.” Sociological Focus 36 (2): 140-41.

Wilson, K. and E.J. Peters. 2005. ““'You can make a place for it”: Remapping Urban First Nations Spaces of Identity." Environment and Planning D: Society and Space 23(3): 395. http://dx.doi.org/10.1068/d390

Williams, D. R. and S. Stewart. 1998. "Sense of Place: An Elusive Concept That is Finding a Home in Ecosystem Management." Journal of Forestry 96 (5): 18-23.

Wotherspoon, T. 2003. "Prospects for a New Middle Class Among Urban Aboriginal People." In Not Strangers in These Parts: Urban Aboriginal Peoples, eds. D. Newhouse and E. J. Peters, 147-65. Ottawa: Policy Research Initiative.

Wuttunee, W. A. 2004. Living Rhythms: Lessons in Aboriginal Economic Resilience and Vision. Montreal and Kingston: McGill Queens University Press.

Young, N. and R. Mathews. 2006. "Young, Nathan, and Ralph Mathews. 2006. "The economic spaces of community and industry in rural British Columbia: the political reconsitution of a rural economy." Paper Presented to the Plenary Session of the Congress of Social Sciences and Humanities. London, Ont.: Canadian International Development Agency. 


\section{APPENDIX A: \\ Urban Aboriginal Economic Development Network \\ The Urban Aboriginal Economic Development Network}

The Urban Aboriginal Economic Development Network (UAED) was formed in 2008 as an open and inclusive multi-stakeholder national network of scholars and practitioners working in urban Aboriginal communities, in universities and governments, and in private industry and non-profits. The Network focuses on mobilizing knowledge on urban Aboriginal economic development, with the goals of strengthening organizations, fostering increased understanding, and building capacity amongst researchers, policy analysts, and community practitioners. The Network is funded by the Social Sciences and Humanities Research Council and Indian and Northern Affairs.

\section{Learning Circles}

The central methodology adopted by the Network was "Learning Circles." A Learning Circle is a small group dialogue designed to encourage people to listen and speak from the heart in a spirit of inquiry. A safe space is created so participants can be trusting, authentic, caring, and open to change. Because the nature of the information we hope will be exchanged between scholars and practitioners, we believe Learning Circles are an appropriate structure for the exchange of knowledge on urban Aboriginal economic development.

\section{Why Use Learning Circles?}

Urban Aboriginal community practitioners face considerable challenges in delivering services and products. They work in an environment with unreliable funding, few supportive institutions, and inconsistent policies and programs that lack strategy. In these ways the urban Aboriginal context is a fractured scene. Creating Learning Circles will bring together practitioners of Aboriginal organizations, and begin to build a common perspective on needs and actions. This format will support the exchange of information on what works for urban Aboriginal organizations, how they can be strengthened, and how their relationships to other organizations can be stronger.

\section{Cultural Perspective}

The Learning Circle - a traditional form of dialogue among North American Aboriginal people - is a grouping of equals based on then concept that "everything is connected," or as stated by the Nuu-chah-Nulth First Nations, hishuk ish ts'awalk - "everything is one." This principle informs the work of seeking to make the whole system visible. Based upon Indigenous sharing 
circles, this traditional way of sharing and building consensus recognizes that it is fundamentally critical for Indigenous people-youth and women in particular-to speak for themselves in their own communities.

Activities

As of March 2011, there have been Learning Circles in Vancouver, Victoria, Edmonton, Sault Ste Marie, Toronto, Halifax, Prince George, Winnipeg, Regina, and Ottawa. As well, the Network has sponsored three National Gatherings, and an academic conference in Regina. 